\begin{tabular}{|l|l|l||}
\hline \multicolumn{2}{|c|}{ PublisherInfo } \\
\hline \hline PublisherName & $:$ & BioMed Central \\
\hline \hline PublisherLocation & $:$ & London \\
\hline \hline PublisherImprintName & $:$ & BioMed Central \\
\hline \hline
\end{tabular}

\title{
Lorazepam for ICU sedation
}

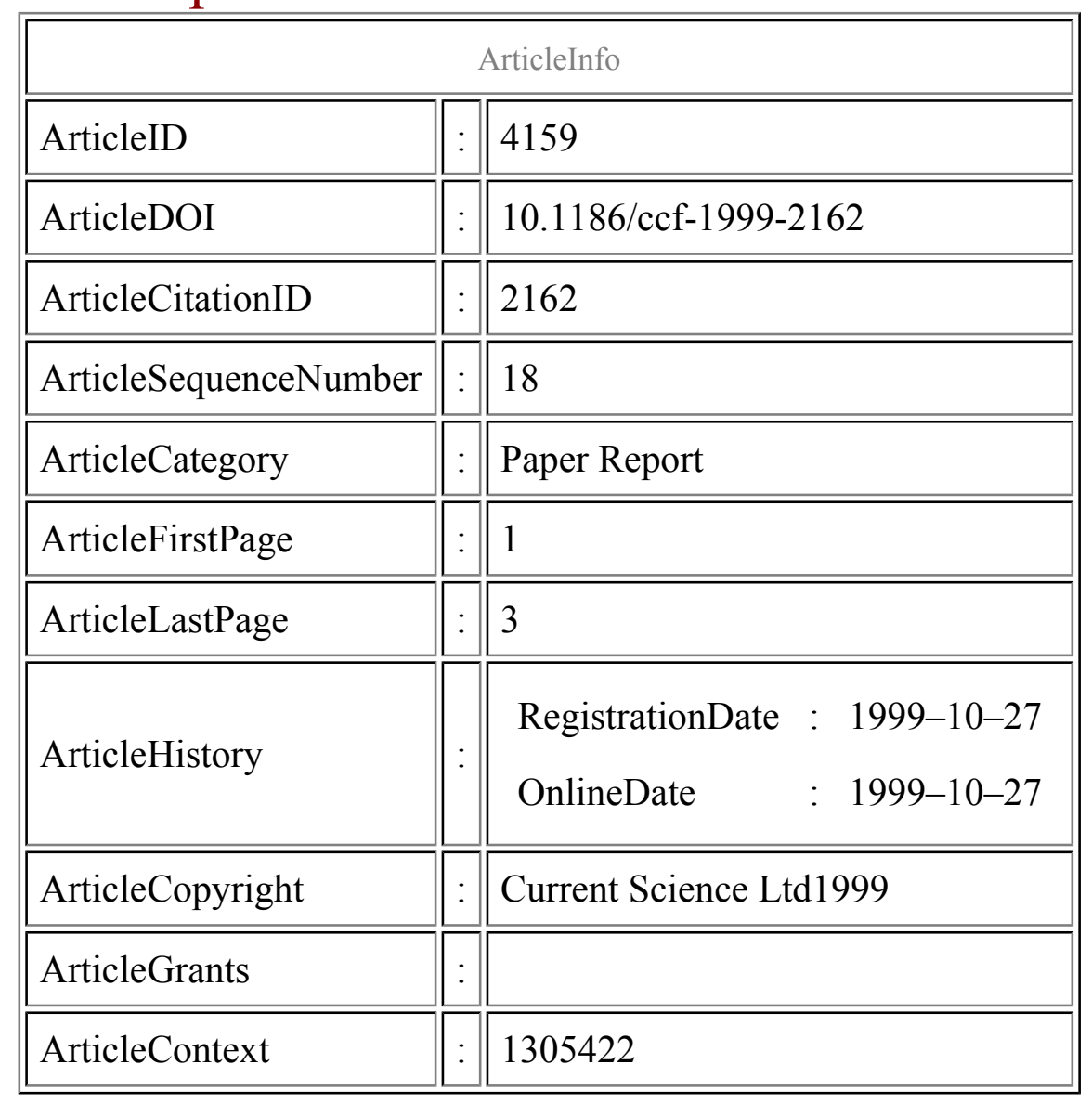




\section{Keywords}

Administration, benzodiazepines, dosage, lorazepam, mechanical ventilation, midazolam, pharmacoeconomics, pharmacokinetics, sedation

\section{Comments}

The confirmation of lorazepam as a useful alternative to the more commonly used midazolam will no doubt encourage further study, particularly with the financial benefits lorazepam infusions may hold for ICU budget holders.

\section{Introduction}

Patients on an intensive care unit (ICU) require sedation for a variety of reasons including reduction of fear, facilitation of ventilation, amnesia and respiratory depression. Both midazolam and lorazepam may be used for sedation by continuous intravenous infusion. Theoretically, midazolam is preferable for its short elimination half-life but, in practice, during long-term infusion the half-life is extended and, with impairment of hepatic and renal function, the half-life of midazolam is further extended. Midazolam is also more expensive than lorazepam.

\section{Aims}

To evaluate the relative effectiveness of midazolam and lorazepam for sedation of ICU patients.

\section{Methods}

In a double-blind randomised controlled trial, 64 adult patients who were likely to require ventilation for more than 3 days were allocated to receive either lorazepam or midazolam infusions. The dose was 
titrated to clinical response and up to a maximum of $60 \mathrm{mg} / \mathrm{h}$ and $4 \mathrm{mg} / \mathrm{h}$ for midazolam and lorazepam, respectively. Sedation was assessed every $8 \mathrm{~h}$, or every $2 \mathrm{~h}$ if sedation was inadequate.

\section{Results}

The study found that sedation was easier to achieve with lorazepam and no difference in recovery was found $24 \mathrm{~h}$ after stopping infusion. The dose of $10 \mathrm{mg}$ midazolam was found to be equipotent to $0.7 \mathrm{mg}$ lorazepam. The cost of midazolam, was on average, 10 times that of lorazepam.

\section{Discussion}

By pharmacological theory, midazolam has the benefit over lorazepam of a short elimination half-life and duration of effect. However, in ICU patients, (particularly in those patients with impaired renal and hepatic function) the duration of effect of midazolam is often prolonged with long infusions. The level of sedation was found to be easier to manage with lorazepam and also cheaper.

\section{References}

1. Swart EL, Strack van Schijndel RJM, van Loenen AC, Thijs LG: Continuous infusion of lorazepam versus midazolam in patients in the intensive care unit: Sedation with lorazepam is easier to manage and is more cost-effective. Crit Care Med. 1999, 27: 1461-1465.

This PDF file was created after publication. 